\title{
Removal of KCNQ2 from Parvalbumin-expressing Interneurons Improves Anti-Seizure Efficacy of Retigabine
}

Corrinne Dunbar ${ }^{1 *}$; Junzhan Jing, $\mathrm{PhD}^{2 *}$; Alina Sonesra ${ }^{1}$; Suhyeorn Park ${ }^{1}$; Heun Soh, PhD ${ }^{3}$; Maxwell Lee ${ }^{1}$; Anastasios Tzingounis, PhD ${ }^{3}$; Edward C. Cooper, $\mathrm{MD}, \mathrm{PhD}^{1,2,4}$; Xiaolong Jiang, PhD ${ }^{2,5}$; ; and Atul Maheshwari, $\mathrm{MD}^{1,2} \mathrm{f}$

*authors contributed equally fco-corresponding authors

${ }^{1}$ Department of Neurology, Baylor College of Medicine; ${ }^{2}$ Department of Neuroscience, Baylor College of Medicine; ${ }^{3}$ Department of Physiology and Neurobiology, University of Connecticut; ${ }^{4}$ Department of Molecular and Human Genetics, Baylor College of Medicine; 5 Jan and Dan Duncan Neurological Research Institute at Texas Children's Hospital

Corresponding authors: Atul Maheshwari, MD and Xiaolong Jiang, PhD

Corresponding author's address: One Baylor Plaza, Houston, TX 77030

Corresponding author's phone and fax: phone: 713-798-0980, fax: 862-208-4979

Corresponding authors' e-mail address: atul.maheshwari@bcm.edu; xiaolonj@bcm.edu

Keywords: retigabine, parvalbumin, interneurons, hippocampus, seizure, Kv7 channel (limit 6)

Number of text pages: 16 (excluding references)

Number of words: 4737

Number of figures: 7 primary figures, 4 supporting information

Number of tables: 0

Number of references: 49

ORCID numbers: 0000-0002-3895-1966 (Dunbar), 0000-0003-4647-0932 (Jing), 0000-0003-3045-7901

(Maheshwari), 0000-0001-8066-1383 (Jiang). 


\section{Abstract:}

Most anti-seizure drugs (ASDs) achieve their effects by suppressing neuronal excitability through various

drug targets. However, these drug targets are widely expressed in both excitatory and inhibitory neurons.

Here, we investigate whether the efficacy of the ASD retigabine (RTG) is altered after removal of the

potassium channel subunit KCNQ2, one of its drug targets, from parvalbumin-expressing interneurons (PV-

INs). Parvalbumin-Cre (PV-Cre) mice were crossed with Kcnq2-floxed (Kcnq2 $\left.{ }^{\mathrm{fl} / \mathrm{fl}}\right)$ mice to conditionally delete

Kcnq2, the gene encoding KCNQ2, from PV-INs. The efficacy of RTG (10 mg/kg, i.p.) in preventing seizures

induced by picrotoxin (PTX, $10 \mathrm{mg} / \mathrm{kg}$, i.p.) and kainic acid (KA, 30mg/kg, i.p.) in conditional knockout mice

(cKO, PV-Kcnq2 $\left.2^{\mathrm{fl} / \mathrm{fl}}\right)$ was tested. Immunostaining for KCNQ2 and KCNQ3 and in vitro pharmacological studies

with whole-cell recordings were also performed. The cKO mice had no significant change in appearance, body

mass, balance, heat sensitivity, depressive behavior, mortality, or EEG spectral power. RTG significantly

delayed the onset of PTX- and KA-induced convulsive seizures in cKO mice, but not in wild-type littermates

(WT). The expression of both KCNQ2 and KCNQ3 subunits was specifically enriched at the distal axon initial

segments (AISs) of hippocampal CA1 PV-INs. In cKO mice, this specific expression and the potassium currents

mediated by these subunits were greatly reduced in PV-INs, while their expression in CA1 pyramidal cells

(CA1-PCs) remained unchanged. Accordingly, while the ability of RTG to suppress CA1-PC spike activity was

unchanged in cKO mice, its suppressive effect on high-frequency spike activity of CA1 PV-INs (elicited by

>540pA depolarizing currents) was significantly reduced compared with WT mice. In addition, the RTG-

induced suppressive effect on intrinsic membrane excitability of PV-INs in WT mice became absent or

decreased in cKO mice. These findings suggest that reducing the suppression of PV-INs by RTG improves its

anticonvulsant effect.

Key words: retigabine, parvalbumin, interneurons, hippocampus, seizure, Kv7 channel 
bioRxiv preprint doi: https://doi.org/10.1101/2020.12.09.417295; this version posted December 9,2020 . The copyright holder for this preprint

(which was not certified by peer review) is the author/funder, who has granted bioRxiv a license to display the preprint in perpetuity. It is made available under aCC-BY-NC-ND 4.0 International license.

Key Points: (3-5 bullets, no longer than 85 characters each)

- RTG was effective for seizures only after Kcnq2 was removed from PV-INs.

- KCNQ2/KCNQ3 was enriched at PV-IN AISs, sites of AP initiation.

- Kcnq2 removal greatly reduced KCNQ2/KCNQ3 expression and function in CA1 PV-INs.

- The suppressive effect of RTG on hippocampal PV-INs was blunted in cKO mice.

- Therefore, the efficacy of RTG may improve with partial sparing of interneurons. 


\section{Introduction}

The primary targets of most anti-seizure drugs (ASDs) generally fall into four major categories: (1) voltagegated sodium channels; (2) voltage-gated calcium channels; (3) ionotropic receptors for neurotransmitters $(\gamma-$ aminobutyric acid and glutamate); and (4) newer molecular targets including the synaptic vesicle protein SV2A and Kv7/KCNQ potassium channels (Rogawski, 2013). It is well known that these drug targets are not specifically confined to excitatory neurons; instead, they are widely expressed across distinct cell types in numerous brain regions, including inhibitory interneurons. Despite constituting a small neuronal population, inhibitory interneurons exert diverse, powerful modulatory influences on excitatory neurons and circuit behavior. It remains an open question in the field if actions of an ASD upon inhibitory neurons may tend to counteract their beneficial effects on excitatory neurons (or vice versa), thereby reducing the efficacy of the ASD.

Retigabine (RTG) is a first-in-class ASD, and the primary mechanism for its anti-seizure effect is to suppress neuronal excitability by promoting the open state of a subfamily of voltage-gated potassium channels formed by KCNQ2-KCNQ5 subunits, encoded by Kcnq2-Kcnq5 (Gunthorpe et al., 2012; Main et al., 2000). KCNQ2-KCNQ5 subunits are expressed in both excitatory neurons and GABAergic interneurons, including parvalbumin-expressing interneurons (PV-INs) (Cooper et al., 2001; Fidzinski et al., 2015, p. 5; Lawrence et al., 2006). To directly assess how RTG's simultaneous effects on inhibitory interneurons contribute to its overall efficacy, we selectively deleted Kcnq2 from PV-INs (Soh et al., 2014), a major population of GABAergic inhibitory interneurons in the cortex (DeFelipe et al., 2013). We then tested whether the sensitivity to RTG with two models of chemoconvulsant-induced seizures could be altered in these conditional $\mathrm{KO}$ mice as well as the effects of RTG on intrinsic and evoked firing properties of both excitatory and inhibitory neurons in vitro. We found that RTG was more effective when its suppressive effects on PV-INs were selectively blunted after Kcnq2 was conditionally removed from PV-INs, warranting the development of cell-type specific ASDs as an important avenue for future investigation. 


\section{Materials and Methods}

\section{Animals}

All experiments were performed according to the guidelines of the Institutional Animal Care and Use Committee of Baylor College of Medicine. Parvalbumin-Cre (PV-Cre) and Ai9 stop-floxed mice (Jackson Laboratory Stock \#008069 and \#007909, respectively), a line shown to have recombination in $>90 \%$ of cells expressing parvalbumin (Hippenmeyer et al., 2005), were crossed with Kcnq2-floxed mice (Kcnq2 ${ }^{\mathrm{fl} / \mathrm{fl}}$ ) (Soh et al., 2014) to generate conditional knockout (cKO, PV-Kcnq2 $\left.2^{\mathrm{fl} / \mathrm{fl}}\right)$ mice with PV-INs labeled with the red fluorescent protein tdTomato on a C57BL6/J background. Mice were group-housed in cages with a natural light-dark cycle and access to a standard pellet diet and water ad libitum. All mice were between postnatal day (P) 30-45 at the time of experiments. In total, 236 wild-type (WT) mice and $157 \mathrm{cKO}$ mice were used in these experiments. Genotype was blinded to investigators prior to analysis. For in vivo and IHC experiments, both male and female mice were used, with no significant differences found between groups; therefore data was pooled together. If necessary, mice were euthanized by $\mathrm{CO}_{2}$ inhalation (SmartBox, Euthanex, Palmer, PA).

\section{In vivo EEG monitoring}

Mice were treated with meloxicam ( $5 \mathrm{mg} / \mathrm{kg}$, Henry Schein Veterinary) and local injection of $50 \mu \mathrm{L}$ of $2 \%$ lidocaine (Henry Schein Veterinary) before being anesthetized with isoflurane $\left(2-4 \%\right.$ in $\mathrm{O}_{2}$; Henry Schein Veterinary). Mice were surgically implanted with bilateral epidural silver wire electrodes over the somatosensory cortex ( $1 \mathrm{~mm}$ posterior and $3 \mathrm{~mm}$ lateral to bregma) and frontal cortex (1 $\mathrm{mm}$ anterior and 1 mm lateral to bregma) (Maheshwari et al., 2013). Reference and ground electrodes were placed over the left and right cerebellum, respectively. Implanted mice received daily meloxicam $(5 \mathrm{mg} / \mathrm{kg})$ injections for 3 days following surgery. Mice were allowed to recover for at least 2 days prior to recording (Soh et al., 2018). Freely moving mice were video-EEG monitored (AD Instruments), and power was analyzed and compared between groups as previously described (Maheshwari et al., 2017). 


\section{Drugs}

Kainic Acid (KA; Santa Cruz Biotechnology) was dissolved in phosphate-buffered saline (PBS; Gibco, Life

Technologies), and retigabine (RTG; Alomone Labs, Inc) and picrotoxin (PTX; Tocris) were first dissolved in dimethyl sulfoxide (DMSO) prior to being diluted to 1\% volume/weight in PBS.

\section{Seizure Monitoring}

Mice were administered RTG 15 minutes prior to PTX or KA injection (RTG and PTX at $10 \mathrm{mg} / \mathrm{kg}$; KA at $30 \mathrm{mg} / \mathrm{kg}$, i.p.), starting between 9:00-11:30 am to prevent confounding diurnal variation. Seizures were defined as rearing and falling with forelimb clonus (Racine Stage 5) (Makinson et al., 2014; Soh et al., 2014). For the PTX experiments, control mice either received no injection or received the vehicle injection (DMSO in PBS) prior to PTX administration. There was no significant difference in induced seizure latency between two cohorts of mice (DMSO in PBS injection $(n=21)$ vs no injection $(n=38)$ ), so these mice were grouped together as 'control' mice. For the KA experiments, control mice received the injection of PBS alone.

\section{Behavioral Testing}

Three behavioral tests were performed over a 3-day period. Mice were randomized to perform either the Tail Suspension Test or the Heat Sensitivity Test on Day 1, followed by the alternate test on Day 2. Mice underwent training for the Balance Beam Assay on both Day 1 and Day 2 prior to final testing on Day 3 as detailed below.

The Tail Suspension Test was utilized to quantify depressive behaviors as previously described (Can et al., 2012). Briefly, the tail was attached to a suspension bar at a height of $50 \mathrm{~cm}$ for six minutes. The total time spent mobile or exhibiting escape behaviors was recorded. The Heat Sensitivity Test was utilized to assess response to painful stimuli (Deuis et al., 2017; Moqrich et al., 2005). Unrestrained mice were placed on a heating pad at $55^{\circ} \mathrm{C}$ and the time until onset of nocifensive behaviors was recorded. Finally, the Balance Beam Assay was utilized to evaluate motor balance and coordination (Luong et al., 2011). A flat, plexiglass beam $(12.7 \mathrm{~mm} \times 6.35 \mathrm{~mm} \times 90 \mathrm{~cm}$ ) was placed at $50 \mathrm{~cm}$ elevation with an aversive light stimulus placed atop the beginning end of the beam. During the first two days of training, each mouse crossed both the $12.7 \mathrm{~mm}$ width 
beam and $6.35 \mathrm{~mm}$ width beam three times. On the third day, the time taken to cross the center $75 \mathrm{~cm}$ of the beam during the two continuous crossings was determined and averaged (Luong et al., 2011). Comparison between groups for behavioral tests was performed with the Mann-Whitney U-test.

\section{Immunohistochemistry}

For KCNQ2 detection in PV-INs expressing tdTomato, we followed a modified fluorescence immunohistochemistry (IHC) protocol used by others (Battefeld et al., 2014). Of note, 2\% paraformaldehyde (PFA) was empirically found to preserve both tdTomato and Kcnq2 antibody fluorescence; higher concentrations of PFA limited the detection of KCNQ2 staining, while lower concentrations limited the detection of tdTomato staining. Mice were perfused transcardially with $20 \mathrm{~mL}$ saline followed by $20 \mathrm{~mL}$ of $2 \%$

PFA. The brain was then removed, post-fixed in 2\% PFA for 30 minutes and then suspended in $30 \%$ sucrose in PBS overnight. $20 \mu \mathrm{m}$ sagittal sections were then cut on a cryotome, incubated first overnight with mouse anti-pan-ankyrin (Rasband et al., 1999) (Sigma, \#S8809) and rabbit anti-KCNQ2 (Cooper et al., 2001) as primary antibodies, followed by Alexa-Fluor goat anti-mouse 647 and goat anti-rabbit Alexa-Fluor 594 (Life

Technologies) as secondary antibodies for one hour. Slices were then incubated in Prolong Gold Antifade with 4',6-diamidino-2-phenylindole (DAPI) prior to imaging with either wide-field or confocal microscopy. Colocalization between KCNQ2 and AnkG was quantified by identifying AIS segments with AnkG expression for at least $20 \mu \mathrm{m}$ (Höfflin et al., 2017) with either the presence or absence of coexpression with KCNQ2.

To detect KCNQ3 in PV-INs, a different IHC protocol was used given poor visualization of KCNQ3 utilizing the KCNQ3 antibody on 2\% PFA-fixed tissue, as previously described (Battefeld et al., 2014). Briefly, PV-INs were filled with Alexa 488 during whole-cell recording. After the recording, the brain slices were immediately fixed with methanol at $-20^{\circ} \mathrm{C}$ for 20 minutes. Slices were then washed with PBS, blocked with non-fat milk, and incubated overnight with mouse anti-pan-ankyrin (Sigma, \#S8809) and guinea pig antiKCNQ3 (Devaux et al., 2004) as primary antibodies, followed by Alexa-Fluor goat anti-mouse 647 and goat anti-guinea pig Alexa-Fluor 594 (Life Technologies) as secondary antibodies for one hour. Slices were then 
incubated in DAPI prior to imaging with either wide-field or confocal microscopy. For all IHC studies, at least

4 mice from each genotype were used.

\section{Slice Preparation and Electrophysiology}

Slice preparation from the mouse hippocampus followed an N-Methyl-D-glucamine (NMDG) slicing protocol (Jiang et al., 2015; Ting et al., 2014). Briefly, female mice (P30-33) were deeply anesthetized using 3\% isoflurane and immediately decapitated. The brain was then immediately removed from the skull and placed into a cold $\left(0-4{ }^{\circ} \mathrm{C}\right)$ oxygenated NMDG solution. Parasagittal slices $(300 \mu \mathrm{m})$ were cut with a vibratome (VT1200, Leica).

The slices were incubated at $34.0 \pm 0.5^{\circ} \mathrm{C}$ in oxygenated NMDG solution for 10-15 minutes before being transferred to an artificial cerebrospinal fluid solution (ACSF) containing: $125 \mathrm{mM} \mathrm{NaCl}, 2.5 \mathrm{mM} \mathrm{KCl}, 1.25 \mathrm{mM}$ $\mathrm{NaH}_{2} \mathrm{PO}_{4}, 25 \mathrm{mM} \mathrm{NaHCO}_{3}, 1 \mathrm{mM} \mathrm{MgCl}_{2}, 25 \mathrm{mM}$ glucose and $2 \mathrm{mM} \mathrm{CaCl}_{2}(\mathrm{pH} 7.4)$ for about $1 \mathrm{~h}$. The slices were then incubated at room temperature for $\sim 0.5-1 \mathrm{~h}$ before recording.

Whole-cell recordings were performed as described previously (Jiang et al., 2015, 2013). Briefly, patch

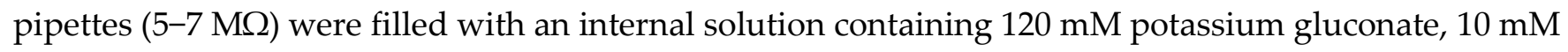
HEPES, $4 \mathrm{mM} \mathrm{KCl}, 4 \mathrm{mM}$ MgATP, $0.3 \mathrm{mM} \mathrm{Na} 3 \mathrm{GTP}, 10 \mathrm{mM}$ sodium phosphocreatine and 0.5\% biocytin (pH 7.25). Whole-cell recordings of CA1 neurons were performed using Quadro EPC 10 amplifiers (HEKA). In many cases, multiple cells were recorded simultaneously (multi-patch recording) in the same slice to improve efficiency in data collection (Jiang et al., 2015, 2013). The spiking activity of each neuron in response to increasing current steps was recorded with or without bath application of RTG $(10 \mu \mathrm{M})$. Recorded neurons were filled with biocytin and then fixed for post hoc morphological recovery to further confirm cell identity (Jiang et al., 2015).

We followed a standard protocol to isolate M-currents $\left(I_{\mathrm{M}}\right)$ from hippocampal neurons (Lawrence et al., 2006; Shah et al., 2002; Soh et al., 2014). Briefly, cells were first clamped at $-20 \mathrm{mV}$, and then a $1 \mathrm{~s} l o n g,-30 \mathrm{mV}$ step was introduced every $15 \mathrm{~s}$ (Fig. 5). A step to $-50 \mathrm{mV}$ forced deactivation of a slowly relaxing outward current that decayed with a time constant of $\sim 130 \mathrm{~ms}$, consistent with the presence of $I_{\mathrm{M}}$ (Fig. 5) (Soh et al., 
bioRxiv preprint doi: https://doi.org/10.1101/2020.12.09.417295; this version posted December $9,2020$. The copyright holder for this preprint (which was not certified by peer review) is the author/funder, who has granted bioRxiv a license to display the preprint in perpetuity. It is made available under aCC-BY-NC-ND 4.0 International license.

2014). After obtaining a 5 min baseline, the KCNQ potassium channels antagonist tetraethylammonium (TEA)

$(0.5 \mathrm{mM})$ was added to the bath and the changes in IM and Ihold were recorded.

\section{Results}

\section{Increased anti-seizure efficacy of RTG in conditional KO mice (cKO, PV-Kcnq2 ${ }^{\mathrm{fl} / \mathrm{fl}}$ )}

Conditional $\mathrm{KO}$ mice $\left(\mathrm{cKO}, \mathrm{PV}-K_{c n q} 2^{\mathrm{fl} / \mathrm{fl}}\right)$ exhibited normal outward appearance and growth throughout development (Fig. 1A, B). Spontaneous seizures were never observed in either genotype. Mortality up to 6 weeks of age was also not different between

genotypes (Fig. 1C). WT and cKO mice had

no significant difference in EEG spectral

power ( $n=5$ for each group, Fig. 1D)

recorded over bilateral parietal regions.

Finally, there were no differences in

performance on the tail suspension, heat

sensitivity, and balance beam tests ( $\mathrm{n}=9-12$

per group, $p>0.05$, Fig. 1E-G). Altogether,

these findings demonstrate that the baseline

phenotype of cKO mice was largely

unchanged.

We first used a picrotoxin (PTX)

seizure induction model to test if the anti-

seizure efficacy of retigabine (RTG), an ASD

targeting KCNQ2-containing channels,
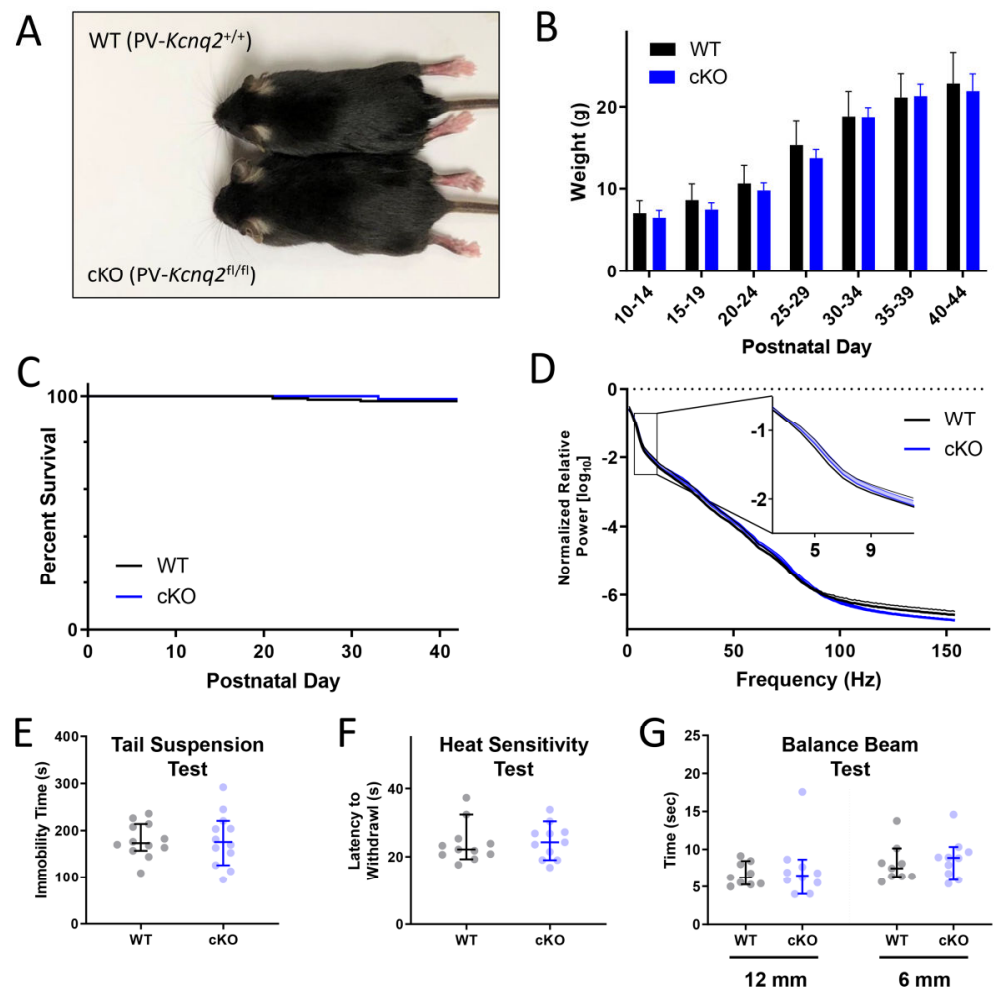

Figure 1. Characterization of $\mathrm{cKO}$ (PV-Kcnq $\left.2^{\mathrm{ff} / \mathrm{fl}}\right)$ mice. (A) Representative WT (PV-Kcnq2 $\left.2^{++}\right)$and littermate cKO mice at P30. (B) No difference in relative growth curves across genotypes $(n=18,10)$. (C) Survival rate of WT $(n=163)$ and cKO mice $(n=101, p>0.05$, Mantel-Cox test) as a function of postnatal day. (D) No difference between genotypes in EEG spectral power at frequencies between $2-150 \mathrm{~Hz}(\mathrm{n}=5$, mean $\pm \mathrm{SEM}, p>0.05$, Tukey's multiple comparisons test). There was also no significant difference between groups in performance on the (E) Tail Suspension Test ( $\mathrm{n}=12$ each, median $\pm 95 \%$ confidence intervals, $p=0.887$, Mann-Whitney U-test), the (F) Heat Sensitivity Test ( $\mathrm{n}=11$ each, $p=0.699)$, or the (G) Balance Beam Test ( $\mathrm{n}=9-10$, $p=0.434$ )

could be altered in cKO where KCNQ2 was selectively removed from PV-INs. PTX-induced seizure semiology in cKO mice was similar to that seen in their WT littermates, including behavioral progression to characteristic 
Racine Stage 5 generalized convulsions (Soh et al., 2018). cKO mice had a shorter latency to seizure onset with PTX challenge than WT littermates (Fig. 2A,2B), as seen previously (Soh et al., 2018). Administration of RTG (10 mg/kg, i.p.) 15 minutes before PTX injection resulted in no significant difference in latency to seizure onset in WT mice when compared to control ( $p=0.405$, Gehan-Breslow-Wilcoxon test, Fig. 2A). In contrast, RTG pretreatment in cKO mice significantly delayed the median time to seizure onset after PTX from 8.12 minutes to 14.51 minutes $(190.2 \% ; p=0.003$, Fig. 2B), indicating that the selective removal of KCNQ2 from PV-INs could improve RTG's anti-seizure efficacy in PTX-induced seizures (drug × genotype interaction on seizure latency: $\mathrm{F}=8.34, p=0.006)$

We then used intraperitoneal kainic acid (KA), another chemoconvulsant with a different induction mechanism, to test if the improved efficacy of RTG in cKO mice was independent of the seizure model.

Aligned with findings from the PTX model, cKO mice had a significantly lower threshold to KA-induced
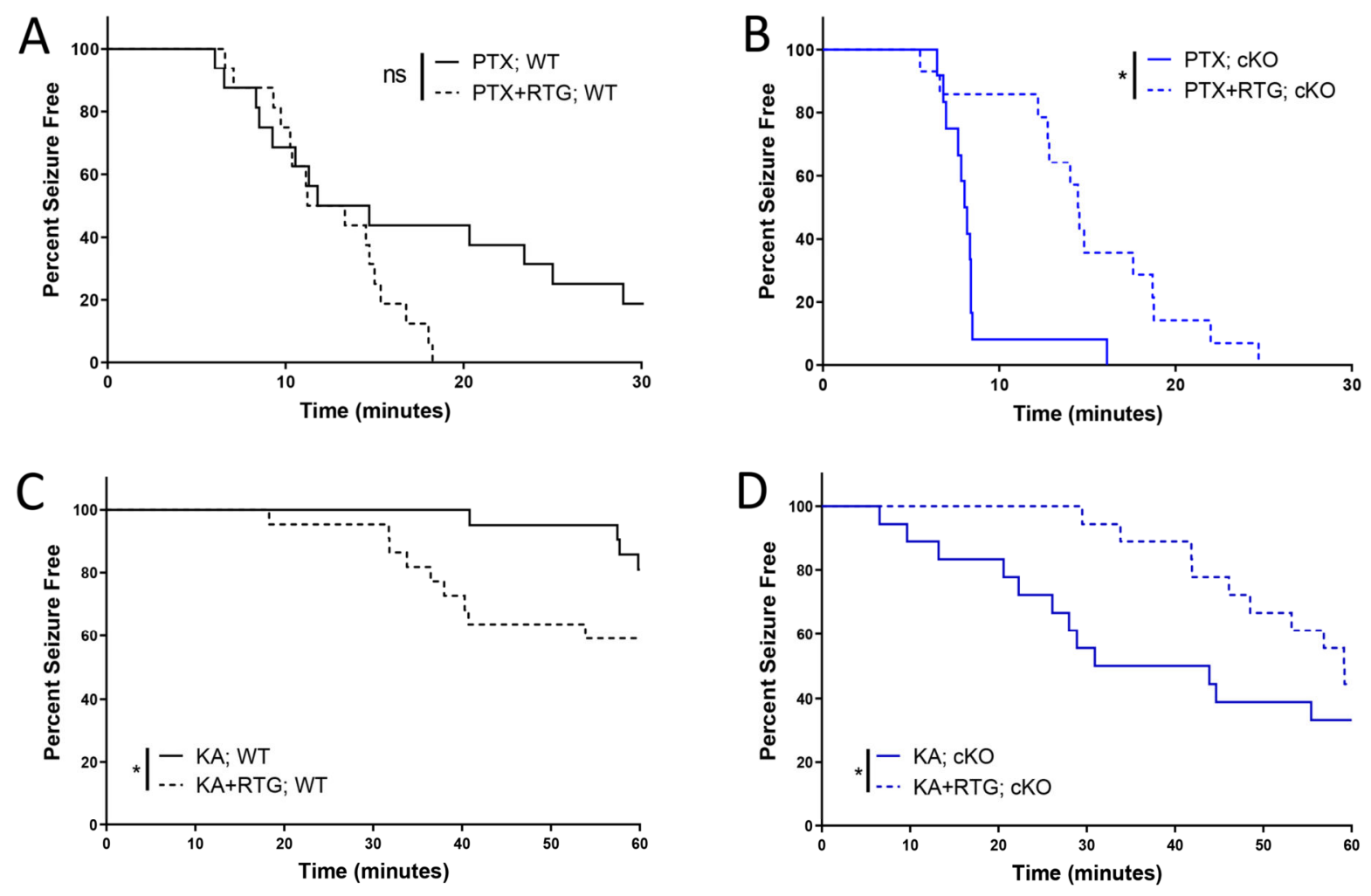

Figure 2. Improved efficacy of RTG in preventing PTX- and KA-induced seizures in cKO mice. Percentage of (A) WT ( $p=0.059$; $\mathrm{n}=16,16)$ and $(\mathrm{B}) \mathrm{cKO}(p=0.001 ; \mathrm{n}=12,14)$ mice remaining seizure free with or without RTG plotted against time after PTX injection (Gehan-Breslow test). Percentage of (C) WT ( $p=0.042 ; n=21,22)$ and (D) cKO $(p=0.040 ; n=18,18)$ mice with or without RTG administration plotted against time after KA injection (Grehan-Breslow test). 
bioRxiv preprint doi: https://doi.org/10.1101/2020.12.09.417295; this version posted December 9, 2020. The copyright holder for this preprint (which was not certified by peer review) is the author/funder, who has granted bioRxiv a license to display the preprint in perpetuity. It is made available under aCC-BY-NC-ND 4.0 International license.

seizures ( $\mathrm{p}<0.001$, Gehan-Breslow Test). In WT mice, administration of RTG (10mg/kg, i.p.) 15 minutes prior to KA injection (30mg/kg, i.p.) resulted in a significantly shorter latency to seizure onset compared to control mice ( $p<0.05$, Grehan-Breslow test, Fig. 2C). In contrast, RTG injection in cKO mice significantly lengthened the seizure latency compared to controls ( $p=0.040$, Fig. 2D), indicating that conditional KO could improve RTG's anti-seizure efficacy in KA-induced seizures as well (drug x genotype interaction on seizure onset: F=15.71, $\mathrm{p}<0.001)$. Of note, PTX- and KA- induced mortality was not significantly different with RTG treatment in either genotype, but there was a trend toward improvement in cKO mice (Fig S1).

\section{Selective loss of KCNQ2 and KCNQ3 expression at AISs of PV-INs in cKO mice}

To confirm KCNQ2 was specifically lost from PV-INs in cKO mice, we performed immunostaining for KCNQ2 and KCNQ3 and imaged cells with wide-field and confocal microscopy (see Methods). Labeling of the AIS in

PV-INs was achieved with the least ambiguity in stratum oriens and stratum radiatum (Fig. 3A, B). In WT mice, CA1 PV-INs had KCNQ2 staining particularly enriched in the distal AIS, overlapping with AnkG (Fig. 3A, C-E). In cKO mice, CA1 PV-INs showed no detectable KCNQ2 staining, consistent with Kcnq2 being knocked out of PV-INs (Fig. 3B, F-H).

\section{KCNQ2 immunostaining was also}

particularly enriched at the distal AIS in WT PV-

INs in the neocortex (Fig. S2A-D), and absent from PV-INs in cKO mice (Fig. S2E-H). In WT mice $(n=4), 175$ out of $177(99.7 \pm 0.003 \%$, mean \pm SEM) AISs counted from non-PV-INs

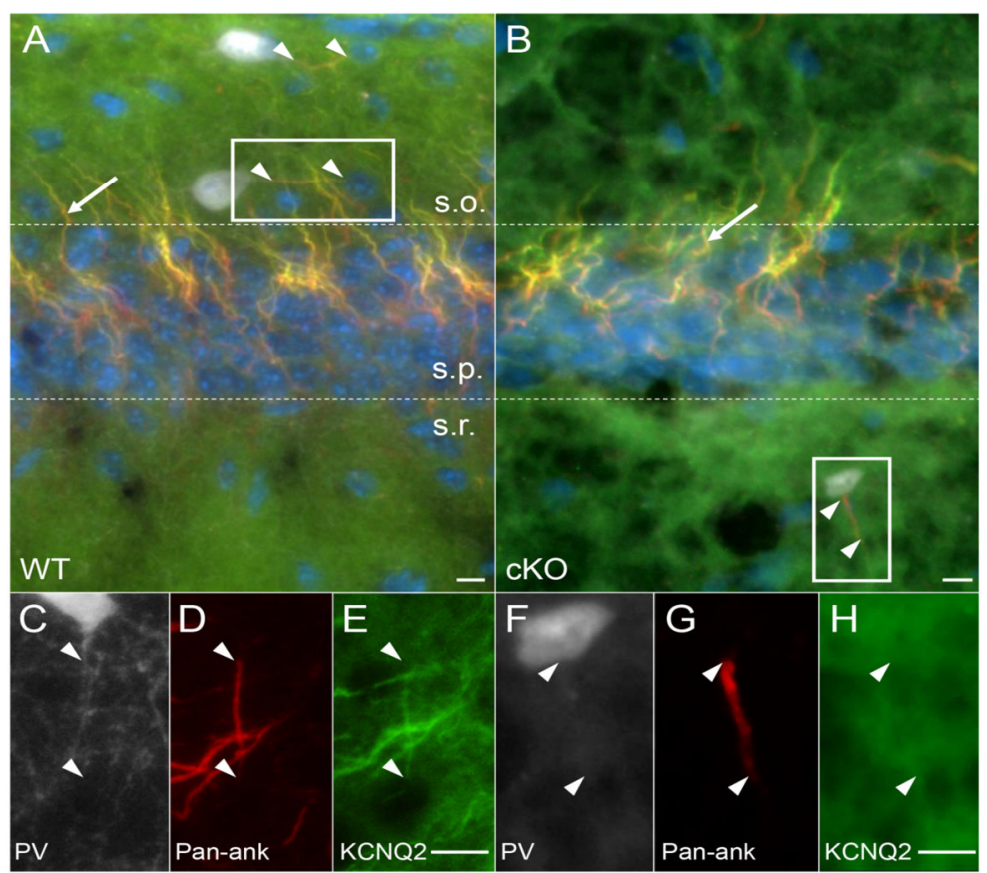

Figure 3. Selective deletion of KCNQ2 from CA 1 PV-IN in cKO mice. (A) In WT mice, KCNQ2 (green) was co-expressed with panankyrin (red, arrowhead) at the distal axon initial segment (AIS) of PV-IN (TdTomato - white) in stratum oriens (s.o. = stratum oriens, s.p. = stratum pyramidale, s.r. = stratum radiatum). (B) In cKO mice, KCNQ2 was no longer co-expressed with pan-ankyrin in PV-IN (here shown in stratum radiatum of CA1), but remained evident in the AIS of CA1 pyramidal cells in stratum pyramidale (arrow). (C-E) Inset from A, showing KCNQ2 expression in the distal 2/3 of the AIS. (F-H) Inset from $\mathrm{B}$, showing absence of KCNQ2 immunoreactivity localized to the PV interneuron AIS. Scales: $10 \mu \mathrm{m}$. 
bioRxiv preprint doi: https://doi.org/10.1101/2020.12.09.417295; this version posted December 9, 2020. The copyright holder for this preprint (which was not certified by peer review) is the author/funder, who has granted bioRxiv a license to display the preprint in perpetuity. It is made available under aCC-BY-NC-ND 4.0 International license.

(positive for AnkG) were positive for KCNQ2 (KCNQ2+). In PV-INs, all of the counted AISs (9 out of 9; 100\%) were KCNQ2+. In cKO mice ( $\mathrm{n}=5)$, almost all AISs (271 of $277 ; 98.3 \pm 0.008 \%$ ) counted from non-PV-INs remained KCNQ2 ${ }^{+}$, but all counted AISs from PV-INs were devoid of KCNQ2 (0\%; 0/15), confirming the selective abolishment of KCNQ2 expression in PV-INs in cKO mice.

Given the high colocalization of KCNQ2 and KCNQ3 (Soh et al., 2014) and the high sensitivity of KCNQ3-containing channels to RTG (Wang et al., 2018), we also imaged the AISs of PVINs of WT and cKO mice after immunostaining for KCNQ3. In WT, KCNQ3 staining was observed in the distal AISs of both CA1 PV-INs and CA1 pyramidal neurons ( $\mathrm{n}=4$, Fig. 4A-D). In cKO mice, KCNQ3 immunostaining was absent in PV-IN AISs (n=4, Fig. 4E-H), but remained detectable in neighboring CA1 pyramidal neurons (Fig. 4E-H). Selective loss or decrease of RTG effect on PV-INs in cKO mice

KCNQ2/3-containing potassium channels are the

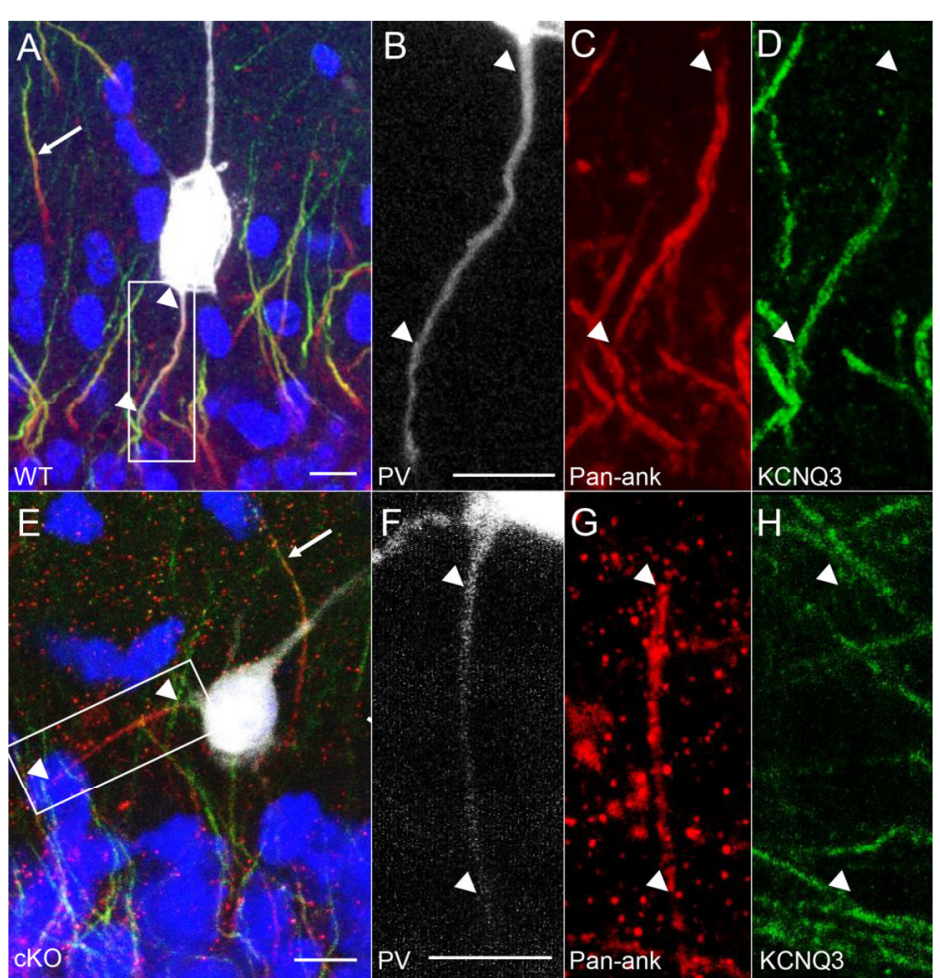

Figure 4. Absence of KCNQ3 AIS labeling in PV-INs in cKO mice. (A-D) With confocal imaging, KCNQ3 (green) expression was seen at the distal AIS (arrowheads) labeled by pan-ankyrin (red) in a WT CA1 stratum pyramidale PV-IN, with non-PV-INs also showing distal AIS labeling of KCNQ3 in the opposite direction (arrow). (E-H) In a PV-IN from the cKO mouse, staining singals for KCNQ3 were absent in the AIS (arrowheads), but detected in the neighboring AIS of a non-PV-IN (arrow). Scale bars: $10 \mu \mathrm{m}$.

major channels mediating M-current $\left(I_{M}\right)$ in hippocampal neurons (Lawrence et al., 2006; Shah et al., 2002; Soh et al., 2014). Given our immunostaining results, we expected the $I_{\mathrm{M}}$ component carried by KCNQ2/3-containing channels to be significantly reduced or abolished by conditional $\mathrm{KO}$. To confirm this, we performed patchclamp recordings on CA1 PV-INs to isolate their IM. In WT PV-INs, the amplitude of $I_{\mathrm{M}}$ was 29.2 $\pm 7.5 \mathrm{pA}$, which could be partially blocked by TEA at $0.5 \mathrm{mM}$, a concentration that blocks the majority of currents carried by KCNQ2/3-containing potassium channels (Fig. 5A, B, left, n=14) (Hadley et al., 2003, 2000; Lawrence et al., 
2006; Shah et al., 2002). In cKO PV-INs, the amplitude of $I_{M}$ induced with the same protocol was significantly

smaller than WT (12.1 $\pm 4.5 \mathrm{pA} ; p<0.05)$, consistent with our previous study (Soh et al., 2014). Importantly, the IM current in cKO mice lost the sensitivity to 0.5 mM TEA (Fig. 5A, B, right, $n=16$ ). There was a significant drug $\times$ genotype interaction on $I_{\mathrm{M}}$ current $(\mathrm{F}=5.8, p=0.023)$, confirming that the current component carried by

KCNQ2/3-containing channels was dramatically reduced or abolished by gene knockout.
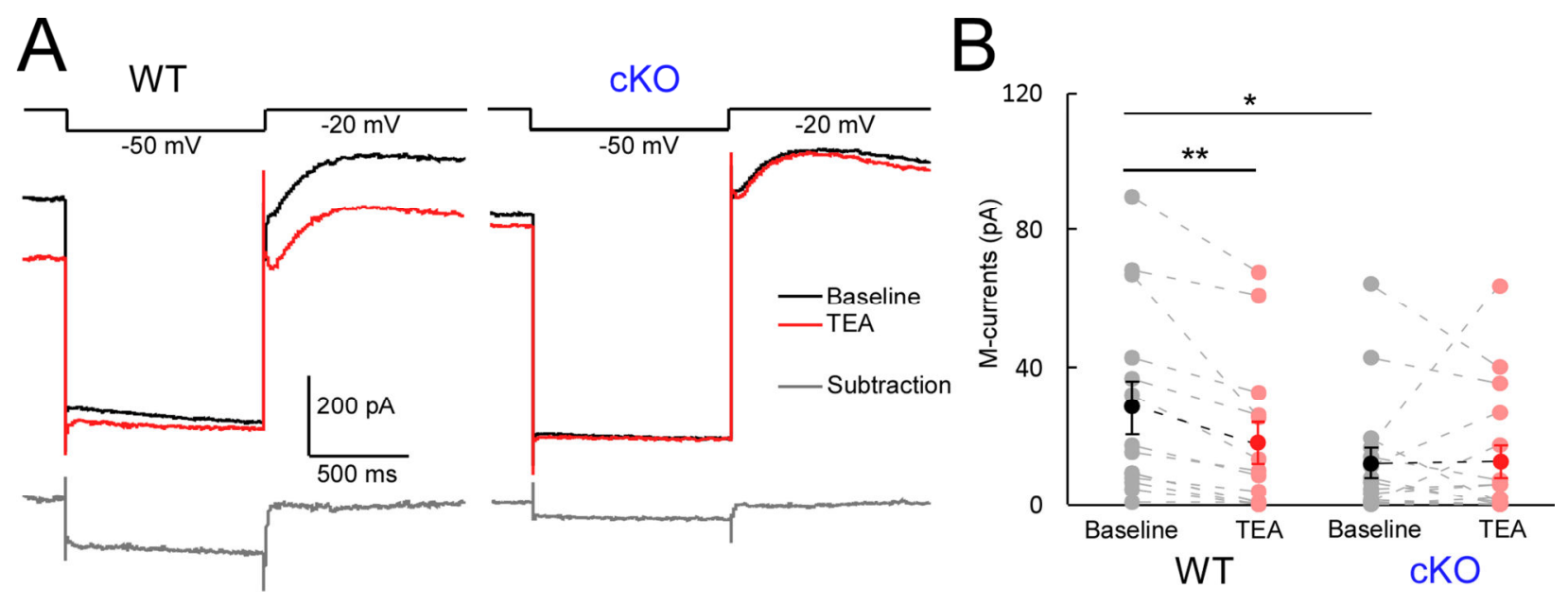

Figure 5. Effects of $0.5 \mathrm{mM}$ tetraethylammonium (TEA) on M-currents of hippocampal PV-INs. (A) Representative traces of Mcurrents (IM) in PV-INs from WT (left) and from cKO (right) before (black) and after (red) $0.5 \mathrm{mM}$ TEA treatment, along with subtraction traces (baseline - TEA, gray). (B) TEA at $0.5 \mathrm{mM}$ significantly reduced the IM amplitude in PV-INs from WT mice (left, $\mathrm{n}=14,{ }^{* *} \mathrm{p}<0.01$ with repeated measures 2-way ANOVA), but TEA at the same concentration did not significantly inhibit $I_{\mathrm{M}}$ in PVINs from cKO mice (right, $\mathrm{n}=16$ ).

Given the above results, we then reasoned that RTG, a KCNQ2/3-containing channel opener, could suppress the excitability of PV-INs, and this effect might be selectively blunted in cKO mice (Grigorov et al., 2014, p. 7; Paz et al., 2018). We thus performed patch-clamp recordings of CA1 pyramidal cells (PC) and PVINs (Fig. 6) to test if there was any specific change for PV-INs in their responses to RTG in cKO mice. Cell responses to depolarizing current steps were recorded, and the number of action potentials (APs) was plotted as a function of the injected current (AP-I curve; Fig. 6B-C). Consistent with our previous findings (Soh et al., 2018), the AP-I curve of PV-INs in cKO slightly shifted left compared to WT when injected currents were mild $(<200$ pA), indicating slightly enhanced excitability of PV-INs in the absence of Kcnq2 (Fig. 6C, D; n=21 PV-INs from 4 WT mice; n=20 PV-INs from 4 cKO mice). AP threshold for PV-INs was not significantly different between the two genotypes $(-38.3 \pm 1.0 \mathrm{mV}$ in $\mathrm{WT}$ vs $-38.9 \pm 0.8 \mathrm{mV}$ in $\mathrm{cKO}, p>0.05)$, suggesting $\mathrm{KCNQ}$ potassium 
bioRxiv preprint doi: https://doi.org/10.1101/2020.12.09.417295; this version posted December 9, 2020. The copyright holder for this preprint (which was not certified by peer review) is the author/funder, who has granted bioRxiv a license to display the preprint in perpetuity. It is made available under aCC-BY-NC-ND 4.0 International license.

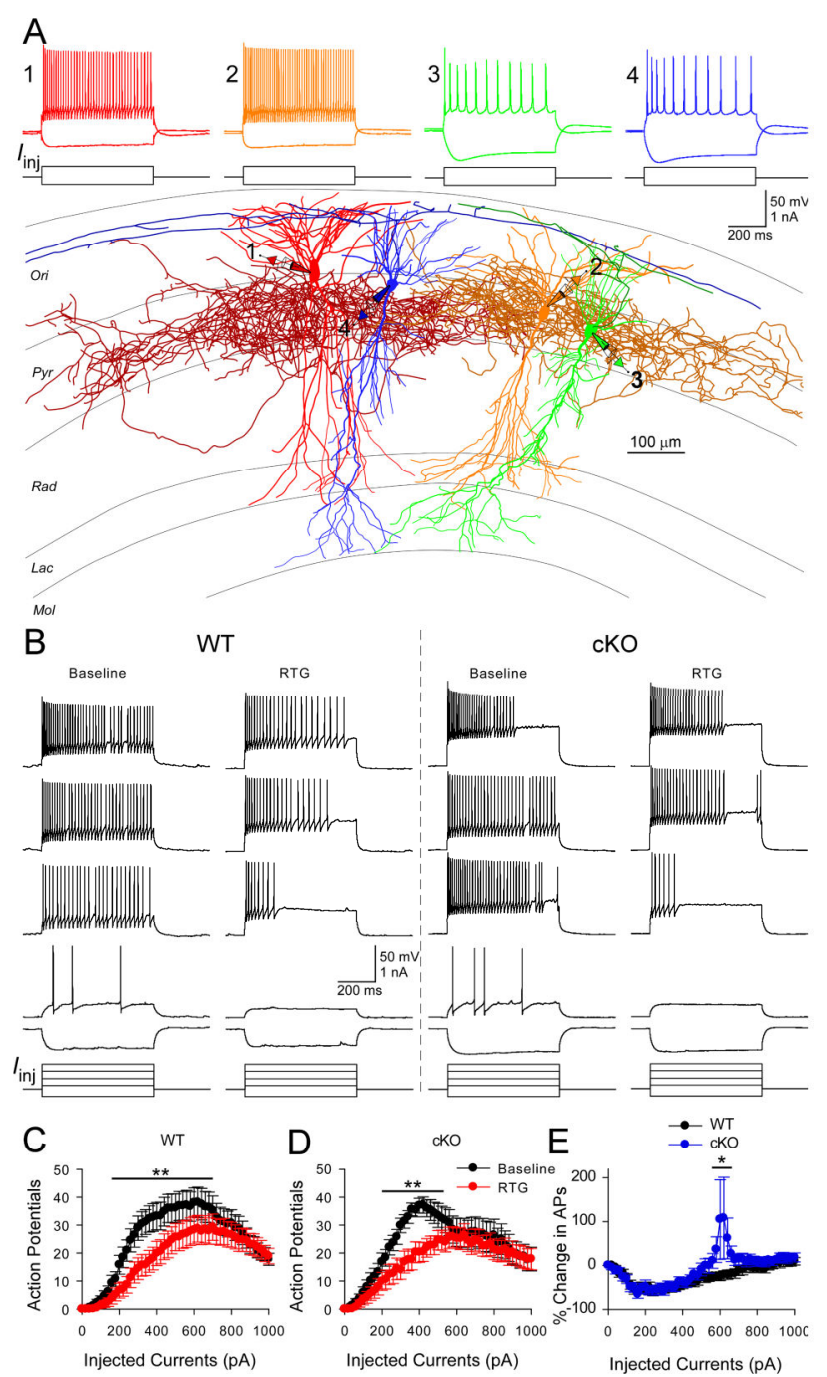

Figure 6. Effects of retigabine (RTG) on the active excitability of PV-INs in vitro. (A) Experimental configuration in CA1. Whole cell recordings were obtained simultaneously from four neurons, including PV-INs $(1,2)$ and PCs $(3,4)$ before and after bath application of RTG $(10 \mu \mathrm{M})$. PV-INs were distinguished from PCs and other interneurons by firing pattern (above) and post hoc morphology recovery (below). (B) Representative membrane voltage responses to different current step injections in PV-INs from WT (left) and cKO (right) before and after RTG application. RTG

suppressed APs in PV-INs in WT (C, n=21, ** $p<0.01$ with repeated measures 2-way ANOVA) and in cKO mice (D, $\mathrm{n}=20,{ }^{* *} p<0.01$ repeated measures 2-way ANOVA). (E) The RTG-induced percentage change of AP number of PV-IN at each current step was calculated, and then was plotted as a function of current step. At higher currents (500-800 pA), RTG was much less effective in suppressing AP of PV-INs in cKO mice ( $\mathrm{n}=21$ in $\mathrm{WT}$ and $\mathrm{n}=20$ in $\mathrm{cKO},{ }^{*} p<0.05$ between $580-640 \mathrm{pA}$ with repeated measures 2-way ANOVA). channels have no prominent effect on AP threshold. Bath application of RTG $(10 \mu \mathrm{M})$ for 10 min significantly reduced the number of APs in response to the majority of the suprathreshold current steps in WT PV-INs (160-700 pA), but the suppressive effect of RTG was evident only when the injected currents were mild and modestly strong in cKO (200-540 pA, Fig. 6B-E). Indeed, AP number induced by current steps above $560 \mathrm{pA}$ in cKO mice barely responded to RTG application (Fig. 6D). To better illustrate the change of RTG effect in cKO mice, we calculated and compared the RTG-induced percentage changes in AP number of PV-INs between the two genotypes at each current step (Fig. 6E). The amplitude and direction of AP number changes in response to RTG started to change in cKO mice when current steps rose above $\sim 500$ pA (Fig. 6E). In the range of $580-640$ pA, the AP responses to RTG were significantly reduced in $\mathrm{cKO}$ compared to WT (Fig. 6E). Importantly, as expected in CA1-PCs, there were no significant differences in AP-I curves between WT and cKO (Fig. S3, n=21 PCs from 3 WT mice; n=24 PCs from 3 cKO mice), and no significant difference in RTG-induced suppression of APs (Fig. S3BD). 
We also examined the effect of RTG on the passive membrane properties of CA1-PCs and PV-INs from

both genotypes. As expected, $10 \mu \mathrm{M}$ RTG could significantly hyperpolarize the resting membrane potential

(RMP) of PV-INs from WT mice (Fig. 7A left, $p<0.01$, Wilcoxon test; n=20 PV-INs from 4 WT mice; n= 20 PV-

INs from 4 cKO mice). However, the RTG effect on RMP was almost absent in cKO mice (Fig. 7A, right; drug $\times$ genotype interaction on RMP: $\mathrm{F}=4.505, p=0.040$ ). There was no significant difference in input resistance of PV-

INs between WT and cKO (Fig. 7B). RTG significantly reduced the input resistance of WT PV-INs (Fig. 7B left, $p<0.01)$, but this effect became significantly smaller in cKO PV-INs $(-3.6 \pm 1.1 \mathrm{mV}$ for WT vs $-0.8 \pm 0.9 \mathrm{mV}$ for $\mathrm{cKO}$, $p=0.05$, unpaired t-test). Together, these findings indicate that RTG could suppress the excitability of PV-INs by hyperpolarizing RMP and reducing input resistance of these neurons, but these effects were decreased or absent in cKO mice.

A
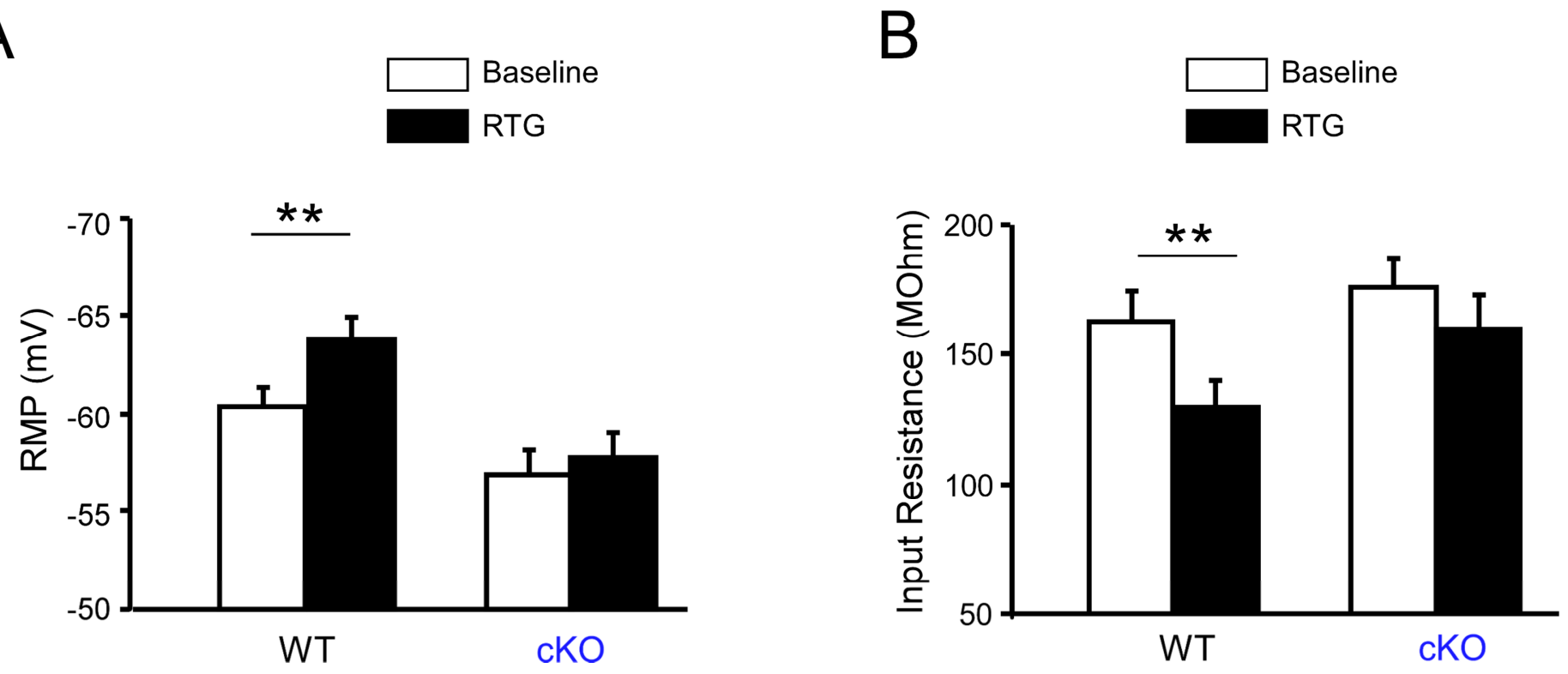

Figure 7. Effect of retigabine (RTG) on the passive membrane properties of hippocampal PV-INs in vitro. (A) Bath application of RTG in hippocampal slices significantly hyperpolarized the RMP of PV-INs from WT mice (n=20, $\left.{ }^{* *} p<0.01\right)$, but not PV-INs from cKO mice. (B) Bath application of RTG significantly reduced the input resistance of PV-INs from WT mice $\left(n=20,{ }^{* *} p<0.01\right)$, but this effect was reduced or absent in cKO mice.

As expected, RTG significantly decreased the input resistance of CA1-PCs, and this effect was not significantly changed in cKO mice (Fig. S4B; n=19 PCs from 3 WT mice; n=24 PCs from 3 cKO mice).

Surprisingly, RTG could not hyperpolarize the RMP of CA1-PCs from WT mice as expected, suggesting the KCNQ channels activated by RTG in CA1-PCs may not contribute to their RMPs; instead, conditional KO of 
Kcnq2 from PV-INs appeared to result in the hyperpolarized RMPs of CA1-PCs (Fig. S4A, left), likely due to a secondary effect of selective gene removal.

\section{Discussion}

The role of inhibitory interneurons (INs) in seizure initiation, propagation, and termination has been controversial, with some studies indicating that IN activity can suppress seizures (Călin et al., 2018; KrookMagnuson et al., 2013; Lu et al., 2016), support seizures (Khoshkhoo et al., 2017; Miri et al., 2018), or both (Assaf and Schiller, 2016; Magloire et al., 2019), depending on the paradigm. To attempt to illuminate this issue, we generated conditional $\mathrm{KO}$ mice $(\mathrm{cKO})$ to remove $\mathrm{KCNQ} 2$ from $\mathrm{PV}^{+}$interneurons and compared the efficacy of RTG, an agonist for KCNQ2-containing channels, in WT and cKO mice in vivo and in vitro. We found that removal of KCNQ2 and KCNQ3 from PV-INs selectively blunted RTG-induced suppression of PVINs and improved RTG's anti-seizure efficacy in two chemoconvulsive seizure models.

\section{Improved anti-seizure efficacy of RTG in cKO mice}

WT and cKO mice had equivalent growth curves, behavior, survival, and baseline EEG spectra (Fig. 1), removing some potential confounds that may have otherwise impacted the seizure threshold. In WT mice, 10 $\mathrm{mg} / \mathrm{kg}$ RTG was ineffective in delaying the onset of seizures when challenged with $10 \mathrm{mg} / \mathrm{kg}$ PTX (Fig. 2). In a prior study using $2.5 \mathrm{mg} / \mathrm{kg}$ PTX, RTG could prevent PTX-induced seizures in a different strain of WT mice, with an ED50 of $18.6 \mathrm{mg} / \mathrm{kg}$ (Rostock et al., 1996). The lack of anti-seizure effects of RTG in our WT mice may have been due to a relatively low dose of RTG and/or high dose of PTX; strain differences are also a possible factor (Frankel, 2009). cKO mice had a significantly lower seizure threshold with PTX challenge, as seen previously (Soh et al., 2018), but RTG significantly delayed seizure onset in these mice, indicating the antiseizure efficacy of RTG could be improved with conditional KO of Kcnq2 from PV-INs.

Given that PV-INs exert influence on network activity via GABAA receptors, the receptors that PTX block, a potential confound could arise from using the PTX seizure model to evaluate the effect of a drug on PV-INs. Therefore, we also used an acute kainic acid (KA) seizure model to further examine if RTG would be 
more effective in cKO mice than in WT mice. After $30 \mathrm{mg} / \mathrm{kg}$ (i.p.) KA injections, RTG significantly hastened seizure onset in WT mice, similar to previous findings in rats (Friedman et al., 2015). In the cKO mice, this paradoxical seizure aggravation with RTG was not only rescued, but reversed. These results suggest that the RTG-indued seizure aggravation in WT mice may be due to its simultaneous suppression of inhibitory PV-INs, and selectively blunting this suppression results in improved anti-seizure efficacy. Seizure aggravation due to an ASD's effect on interneurons has also been postulated in other seizure models. For example, PV-IN dysfunction has been well-described in mouse models of Dravet Syndrome, which carry mutations in the Scn1a sodium channel subunit (Ogiwara et al., 2007; Yu et al., 2006). ASDs that block sodium channels exacerbate seizures in both patients and mice with this mutation, presumably due to their simultaneous suppression of PV-IN activity. In addition, in the stargazer mouse model of absence epilepsy, we have also found ASD-induced paradoxical seizure exacerbation to be linked to its simultaneous suppression of inhibitory neurons (Maheshwari et al., 2013). These results suggest that sparing GABAergic interneurons, such as PV-INs, may be a desirable strategy for preventing seizures, while a cell-autonomous drug effect may be less effective.

\section{Cell type-specific distribution and role of $K C N Q 2 / 3$ in the cortex}

In this study, we found that the expression of both KCNQ2 and KCNQ3 were specifically enriched in the AIS of PV-INs in the hippocampal CA1 region. Deletion of Kcnq2 from PV-INs removed the expression of KCNQ2 in the AIS, but it was also sufficient to remove the expression of KCNQ3 in PV-INs, consistent with our previous finding in pyramidal cells (Soh et al., 2014). Further investigation may be needed to understand the mechanism underlying the subsequent loss of KCNQ3 subunits upon removal of KCNQ2 and whether compensatory mechanisms are present at different stages of development (Carver and Shapiro, 2019). Our findings in PV-INs corroborate and extend previous findings in neocortical pyramidal cells (PCs) (Battefeld et al., 2014; Soh et al., 2014), highlighting the highly compartmentalized functions of KCNQ channels across cell types. Nevertheless, it may not be the case that all cell types have such a highly restricted KCNQ channel 
expression. For instance, hippocampal CA1-PCs and somatostatin-expressing interneurons appear to have a high density of somatic KCNQ2/3 and prominent somatic M currents, in addition to having these channels highly expressed in the AIS (Cooper et al., 2001; Lawrence et al., 2006).

\section{Selective loss or decrease of RTG effect on PV-INs in cKO mice}

As expected, RTG reduced spike frequency of PV-INs elicited by depolarizing current steps, reduced input resistance, and hyperpolarized the RMP. Similar effects were observed in somatosensory L5 PCs upon the activation of KCNQ2/3-containing potassium channels, which are also specifically enriched in the AIS of these neurons (Battefeld et al., 2014). Interestingly, while activating KCNQ2/3-containing channels in CA1-PCs by RTG dampened their spiking activity as expected, RTG did not induce any significant change in the somatic RMPs of CA1-PCs, which was different from what we observed in PV-INs, but consistent with previous studies on CA1-PCs (Soh et al., 2014). This result suggests that somatic KCNQ2-5 channels in CA1-PCs may play a much smaller role in regulating excitability at rest than these channels do in PV-INs. This differential effect across cell types may be due to a more hyperpolarized RMP of CA1-PCs than PV-INs and neocortical L5 PCs. Under our recording conditions, CA1-PCs have an RMP that is near the foot of the voltage-gated activation curve for KCNQ2-5 channels, and the fraction of somatic channels that are active at the RMP would thus be lower in the PCs compared with PV-INs. Interestingly, while RTG had no significant effect on the RMP of CA1-PCs, the RMP of CA1-PCs became more hyperpolarized when Kcnq2 was selectively removed from PV-INs. This indirect effect may be due to homeostatic compensation in order to counterbalance the more excitable PV-INs in cKO mice (Soh et al., 2018).

Surprisingly, RTG was still able to suppress the firing of CA1 PV-INs for injected currents of up to $\sim 500$ pA in cKO mice where both KCNQ2/3 were abolished in PV-INs (Fig. 6). This RTG-sensitive, residual component may be related to incomplete removal of KCNQ2/3 heterotetramers, the presence of KCNQ5 homotetramers or KCNQ3/5 heterotetramers (Fidzinski et al., 2015, p. 5), or non-Kv7, “off-target” effects of 
effect on APs of PV-INs became absent or opposite in cKO mice (Fig. 6E). In addition, RTG also reduced input resistance and hyperpolarized RMPs in WT PV-INs, but this effect became absent or decreased in cKO PV-INs. Consistent with the selective removal of KCNQ2 from PV-INs, these effects were not observed in CA1-PCs from cKO mice.

There are some limitations to our study. First, Kcnq2 deletion was cell-type restrictive but not developmentally restricted, and thus could change the network in ways that may affect seizure characteristics. Nevertheless, PTX- and KA-induced seizure semiologies of cKO and WT mice were similar, including behavioral progression to characteristic Racine Stage 5 generalized convulsions (Soh et al., 2018). In addition, our studies were performed on chemoconvulsant-induced seizures, and validation of our findings in models of spontaneous, recurrent, and pharmacoresistant seizures would enhance the generalizability of these findings. Finally, the current focus was on PV-INs, but further study should include exploring how drug effects on various other interneuron subtypes impact their anti-seizure efficacy (Tremblay et al., 2016). Our findings may also have important implications for ASD pharmacoresistance. ASDs are ineffective in about one-third of patients with epilepsy (Kwan and Brodie, 2000; Tang et al., 2017). The target hypothesis of pharmacoresistance suggests that drug effect is limited by altered expression of its targets (Pohlmann-Eden and Weaver, 2013), while the intrinsic severity hypothesis posits that pharmacoresistance develops as the underlying disease process becomes more severe (Rogawski, 2013). Despite the greater severity of seizures, cKO mice responded more favorably to RTG than WT littermates. Our findings thus provide support for the target hypothesis over the intrinsic severity hypothesis. It will be interesting to see if this conclusion is sustained through the extension of this approach to a broader range of seizure models. 


\section{Acknowledgments}

We acknowledge funding from NINDS R01 NS101596 (AT), NINDS R01 NS49119 and the Jack Pribaz

Foundation (ECC), NIMH R01 MH109556 (JJ, XJ), and NINDS K08 NS096029 (AM).

\section{Disclosure of Conflicts of Interest}

AM receives funding from NeuCyte, Inc to perform studies that are independent from this research. ECC

serves as a consultant to Knopp Biosciences and Xenon Pharmaceuticals, which develops products related to the research being reported. The terms of this arrangement have been reviewed and approved by the Baylor College of Medicine in accordance with its policy on Financial Conflicts of Interests in Research. The remaining authors have no conflicts of interest.

\section{Ethical Publication Statement}

We confirm that we have read the Journal's position on issues involved in ethical publication and affirm that this report is consistent with those guidelines. 


\section{References}

Assaf, F., Schiller, Y., 2016. The antiepileptic and ictogenic effects of optogenetic neurostimulation of PV-expressing interneurons. J. Neurophysiol. 116, 1694-1704. https://doi.org/10.1152/jn.00744.2015

Battefeld, A., Tran, B.T., Gavrilis, J., Cooper, E.C., Kole, M.H.P., 2014. Heteromeric Kv7.2/7.3 channels differentially regulate action potential initiation and conduction in neocortical myelinated axons. J. Neurosci. Off. J. Soc. Neurosci. 34, 3719-3732. https://doi.org/10.1523/JNEUROSCI.4206-13.2014

Cǎlin, A., Stancu, M., Zagrean, A.-M., Jefferys, J.G.R., Ilie, A.S., Akerman, C.J., 2018. Chemogenetic Recruitment of Specific Interneurons Suppresses Seizure Activity. Front. Cell. Neurosci. 12. https://doi.org/10.3389/fncel.2018.00293

Can, A., Dao, D.T., Terrillion, C.E., Piantadosi, S.C., Bhat, S., Gould, T.D., 2012. The Tail Suspension Test. J. Vis. Exp. JoVE. https://doi.org/10.3791/3769

Carver, C.M., Shapiro, M.S., 2019. Gq-Coupled Muscarinic Receptor Enhancement of KCNQ2/3 Channels and Activation of TRPC Channels in Multimodal Control of Excitability in Dentate Gyrus Granule Cells. J. Neurosci. Off. J. Soc. Neurosci. 39, 1566-1587. https://doi.org/10.1523/JNEUROSCI.1781-18.2018

Cooper, E.C., Harrington, E., Jan, Y.N., Jan, L.Y., 2001. M channel KCNQ2 subunits are localized to key sites for control of neuronal network oscillations and synchronization in mouse brain. J. Neurosci. Off. J. Soc. Neurosci. 21, 95299540.

DeFelipe, J., López-Cruz, P.L., Benavides-Piccione, R., Bielza, C., Larrañaga, P., Anderson, S., Burkhalter, A., Cauli, B., Fairén, A., Feldmeyer, D., Fishell, G., Fitzpatrick, D., Freund, T.F., González-Burgos, G., Hestrin, S., Hill, S., Hof, P.R., Huang, J., Jones, E.G., Kawaguchi, Y., Kisvárday, Z., Kubota, Y., Lewis, D.A., Marín, O., Markram, H., McBain, C.J., Meyer, H.S., Monyer, H., Nelson, S.B., Rockland, K., Rossier, J., Rubenstein, J.L.R., Rudy, B., Scanziani, M., Shepherd, G.M., Sherwood, C.C., Staiger, J.F., Tamás, G., Thomson, A., Wang, Y., Yuste, R., Ascoli, G.A., 2013. New insights into the classification and nomenclature of cortical GABAergic interneurons. Nat. Rev. Neurosci. 14, 202-216. https://doi.org/10.1038/nrn3444

Deuis, J.R., Dvorakova, L.S., Vetter, I., 2017. Methods Used to Evaluate Pain Behaviors in Rodents. Front. Mol. Neurosci. 10. https://doi.org/10.3389/fnmol.2017.00284

Devaux, J.J., Kleopa, K.A., Cooper, E.C., Scherer, S.S., 2004. KCNQ2 is a nodal K+ channel. J. Neurosci. Off. J. Soc. Neurosci. 24, 1236-1244. https://doi.org/10.1523/JNEUROSCI.4512-03.2004

Fidzinski, P., Korotkova, T., Heidenreich, M., Maier, N., Schuetze, S., Kobler, O., Zuschratter, W., Schmitz, D., Ponomarenko, A., Jentsch, T.J., 2015. KCNQ5 K(+) channels control hippocampal synaptic inhibition and fast network oscillations. Nat. Commun. 6, 6254. https://doi.org/10.1038/ncomms7254

Frankel, W.N., 2009. Genetics of complex neurological disease: challenges and opportunities for modeling epilepsy in mice and rats. Trends Genet. TIG 25, 361-367. https://doi.org/10.1016/j.tig.2009.07.001

Friedman, L.K., Slomko, A.M., Wongvravit, J.P., Naseer, Z., Hu, S., Wan, W.Y., Ali, S.S., 2015. Efficacy of Retigabine on Acute Limbic Seizures in Adult Rats. J. Epilepsy Res. 5, 46-59. https://doi.org/10.14581/jer.15010

Grigorov, A., Moskalyuk, A., Kravchenko, M., Veselovsky, N., Verkhratsky, A., Fedulova, S., 2014. Kv7 potassium channel subunits and $M$ currents in cultured hippocampal interneurons. Pflugers Arch. 466, 1747-1758. https://doi.org/10.1007/s00424-013-1406-x

Gunthorpe, M.J., Large, C.H., Sankar, R., 2012. The mechanism of action of retigabine (ezogabine), a first-in-class K+ channel opener for the treatment of epilepsy. Epilepsia 53, 412-424. https://doi.org/10.1111/j.15281167.2011.03365.x

Hadley, J.K., Noda, M., Selyanko, A.A., Wood, I.C., Abogadie, F.C., Brown, D.A., 2000. Differential tetraethylammonium sensitivity of KCNQ1-4 potassium channels. Br. J. Pharmacol. 129, 413-415. https://doi.org/10.1038/sj.bjp.0703086

Hadley, J.K., Passmore, G.M., Tatulian, L., Al-Qatari, M., Ye, F., Wickenden, A.D., Brown, D.A., 2003. Stoichiometry of expressed KCNQ2/KCNQ3 potassium channels and subunit composition of native ganglionic $\mathrm{M}$ channels deduced from block by tetraethylammonium. J. Neurosci. Off. J. Soc. Neurosci. 23, 5012-5019.

Hippenmeyer, S., Vrieseling, E., Sigrist, M., Portmann, T., Laengle, C., Ladle, D.R., Arber, S., 2005. A developmental switch in the response of DRG neurons to ETS transcription factor signaling. PLoS Biol. 3, e159. https://doi.org/10.1371/journal.pbio.0030159

Höfflin, F., Jack, A., Riedel, C., Mack-Bucher, J., Roos, J., Corcelli, C., Schultz, C., Wahle, P., Engelhardt, M., 2017. Heterogeneity of the Axon Initial Segment in Interneurons and Pyramidal Cells of Rodent Visual Cortex. Front. Cell. Neurosci. 11, 332. https://doi.org/10.3389/fncel.2017.00332 

available under aCC-BY-NC-ND 4.0 International license.

Jiang, X., Shen, S., Cadwell, C.R., Berens, P., Sinz, F., Ecker, A.S., Patel, S., Tolias, A.S., 2015. Principles of connectivity among morphologically defined cell types in adult neocortex. Science 350, aac9462. https://doi.org/10.1126/science.aac9462

Jiang, X., Wang, G., Lee, A.J., Stornetta, R.L., Zhu, J.J., 2013. The organization of two new cortical interneuronal circuits. Nat. Neurosci. 16, 210-218. https://doi.org/10.1038/nn.3305

Khoshkhoo, S., Vogt, D., Sohal, V.S., 2017. Dynamic, Cell-Type-Specific Roles for GABAergic Interneurons in a Mouse Model of Optogenetically Inducible Seizures. Neuron 93, 291-298.

https://doi.org/10.1016/j.neuron.2016.11.043

Krook-Magnuson, E., Armstrong, C., Oijala, M., Soltesz, I., 2013. On-demand optogenetic control of spontaneous seizures in temporal lobe epilepsy. Nat. Commun. 4, 1376. https://doi.org/10.1038/ncomms2376

Kwan, P., Brodie, M.J., 2000. Early identification of refractory epilepsy. N. Engl. J. Med. 342, 314-319. https://doi.org/10.1056/NEJM200002033420503

Lawrence, J.J., Saraga, F., Churchill, J.F., Statland, J.M., Travis, K.E., Skinner, F.K., McBain, C.J., 2006. Somatodendritic Kv7/KCNQ/M channels control interspike interval in hippocampal interneurons. J. Neurosci. Off. J. Soc. Neurosci. 26, 12325-12338. https://doi.org/10.1523/JNEUROSCI.3521-06.2006

Lu, Y., Zhong, C., Wang, Lulu, Wei, P., He, W., Huang, K., Zhang, Y., Zhan, Y., Feng, G., Wang, Liping, 2016. Optogenetic dissection of ictal propagation in the hippocampal-entorhinal cortex structures. Nat. Commun. 7, 10962. https://doi.org/10.1038/ncomms10962

Luong, T.N., Carlisle, H.J., Southwell, A., Patterson, P.H., 2011. Assessment of Motor Balance and Coordination in Mice using the Balance Beam. J. Vis. Exp. JoVE. https://doi.org/10.3791/2376

Magloire, V., Cornford, J., Lieb, A., Kullmann, D.M., Pavlov, I., 2019. KCC2 overexpression prevents the paradoxical seizure-promoting action of somatic inhibition. Nat. Commun. 10, 1225. https://doi.org/10.1038/s41467-01908933-4

Maheshwari, A., Akbar, A., Wang, M., Marks, R., Yu, K., Park, S., Foster, B.L., Noebels, J.L., 2017. Persistent aberrant cortical phase-amplitude coupling following seizure treatment in absence epilepsy models. J. Physiol. https://doi.org/10.1113/JP274696

Maheshwari, A., Nahm, W.K., Noebels, J.L., 2013. Paradoxical proepileptic response to NMDA receptor blockade linked to cortical interneuron defect in stargazer mice. Front. Cell. Neurosci. 7, 156.

https://doi.org/10.3389/fncel.2013.00156

Main, M.J., Cryan, J.E., Dupere, J.R., Cox, B., Clare, J.J., Burbidge, S.A., 2000. Modulation of KCNQ2/3 potassium channels by the novel anticonvulsant retigabine. Mol. Pharmacol. 58, 253-262.

Makinson, C.D., Tanaka, B.S., Lamar, T., Goldin, A.L., Escayg, A., 2014. Role of the hippocampus in Nav1.6 (Scn8a) mediated seizure resistance. Neurobiol. Dis. 68, 16-25. https://doi.org/10.1016/j.nbd.2014.03.014

Miri, M.L., Vinck, M., Pant, R., Cardin, J.A., 2018. Altered hippocampal interneuron activity precedes ictal onset. eLife 7. https://doi.org/10.7554/eLife.40750

Moqrich, A., Hwang, S.W., Earley, T.J., Petrus, M.J., Murray, A.N., Spencer, K.S.R., Andahazy, M., Story, G.M., Patapoutian, A., 2005. Impaired Thermosensation in Mice Lacking TRPV3, a Heat and Camphor Sensor in the Skin. Science 307, 1468-1472. https://doi.org/10.1126/science.1108609

Ogiwara, I., Miyamoto, H., Morita, N., Atapour, N., Mazaki, E., Inoue, I., Takeuchi, T., Itohara, S., Yanagawa, Y., Obata, K., Furuichi, T., Hensch, T.K., Yamakawa, K., 2007. Nav1.1 localizes to axons of parvalbumin-positive inhibitory interneurons: a circuit basis for epileptic seizures in mice carrying an Scn1a gene mutation. J. Neurosci. Off. J. Soc. Neurosci. 27, 5903-5914. https://doi.org/10.1523/JNEUROSCI.5270-06.2007

Otto, J.F., Kimball, M.M., Wilcox, K.S., 2002. Effects of the anticonvulsant retigabine on cultured cortical neurons: changes in electroresponsive properties and synaptic transmission. Mol. Pharmacol. 61, 921-927. https://doi.org/10.1124/mol.61.4.921

Paz, R.M., Tubert, C., Stahl, A., Díaz, A.L., Etchenique, R., Murer, M.G., Rela, L., 2018. Inhibition of striatal cholinergic interneuron activity by the Kv7 opener retigabine and the nonsteroidal anti-inflammatory drug diclofenac. Neuropharmacology 137, 309-321. https://doi.org/10.1016/j.neuropharm.2018.05.010

Pohlmann-Eden, B., Weaver, D.F., 2013. The puzzle(s) of pharmacoresistant epilepsy. Epilepsia 54 Suppl 2, 1-4. https://doi.org/10.1111/epi.12174

Rasband, M.N., Peles, E., Trimmer, J.S., Levinson, S.R., Lux, S.E., Shrager, P., 1999. Dependence of nodal sodium channel clustering on paranodal axoglial contact in the developing CNS. J. Neurosci. Off. J. Soc. Neurosci. 19, 7516-7528. 
Rogawski, M.A., 2013. The intrinsic severity hypothesis of pharmacoresistance to antiepileptic drugs. Epilepsia 54, 3340. https://doi.org/10.1111/epi.12182

Rostock, A., Tober, C., Rundfeldt, C., Bartsch, R., Engel, J., Polymeropoulos, E.E., Kutscher, B., Löscher, W., Hönack, D., White, H.S., Wolf, H.H., 1996. D-23129: a new anticonvulsant with a broad spectrum activity in animal models of epileptic seizures. Epilepsy Res. 23, 211-223.

Shah, M.M., Mistry, M., Marsh, S.J., Brown, D.A., Delmas, P., 2002. Molecular correlates of the M-current in cultured rat hippocampal neurons. J. Physiol. 544, 29-37. https://doi.org/10.1113/jphysiol.2002.028571

Soh, H., Pant, R., LoTurco, J.J., Tzingounis, A.V., 2014. Conditional deletions of epilepsy-associated KCNQ2 and KCNQ3 channels from cerebral cortex cause differential effects on neuronal excitability. J. Neurosci. Off. J. Soc. Neurosci. 34, 5311-5321. https://doi.org/10.1523/JNEUROSCI.3919-13.2014

Soh, H., Park, S., Ryan, K., Springer, K., Maheshwari, A., Tzingounis, A.V., 2018. Deletion of KCNQ2/3 potassium channels from $\mathrm{PV}+$ interneurons leads to homeostatic potentiation of excitatory transmission. eLife 7. https://doi.org/10.7554/eLife.38617

Tang, F., Hartz, A.M.S., Bauer, B., 2017. Drug-Resistant Epilepsy: Multiple Hypotheses, Few Answers. Front. Neurol. 8, 301. https://doi.org/10.3389/fneur.2017.00301

Ting, J.T., Daigle, T.L., Chen, Q., Feng, G., 2014. Acute Brain Slice Methods for Adult and Aging Animals: Application of Targeted Patch Clamp Analysis and Optogenetics, in: Martina, M., Taverna, S. (Eds.), Patch-Clamp Methods and Protocols. Springer New York, New York, NY, pp. 221-242. https://doi.org/10.1007/978-1-4939-1096-0_14

Tremblay, R., Lee, S., Rudy, B., 2016. GABAergic Interneurons in the Neocortex: From Cellular Properties to Circuits. Neuron 91, 260-292. https://doi.org/10.1016/j.neuron.2016.06.033

Treven, M., Koenig, X., Assadpour, E., Gantumur, E., Meyer, C., Hilber, K., Boehm, S., Kubista, H., 2015. The anticonvulsant retigabine is a subtype selective modulator of GABAA receptors. Epilepsia 56, 647-657. https://doi.org/10.1111/epi.12950

Wang, A.W., Yau, M.C., Wang, C.K., Sharmin, N., Yang, R.Y., Pless, S.A., Kurata, H.T., 2018. Four drug-sensitive subunits are required for maximal effect of a voltage sensor-targeted KCNQ opener. J. Gen. Physiol. 150, 1432-1443. https://doi.org/10.1085/jgp.201812014

Yu, F.H., Mantegazza, M., Westenbroek, R.E., Robbins, C.A., Kalume, F., Burton, K.A., Spain, W.J., McKnight, G.S., Scheuer, T., Catterall, W.A., 2006. Reduced sodium current in GABAergic interneurons in a mouse model of severe myoclonic epilepsy in infancy. Nat. Neurosci. 9, 1142-1149. https://doi.org/10.1038/nn1754 
A

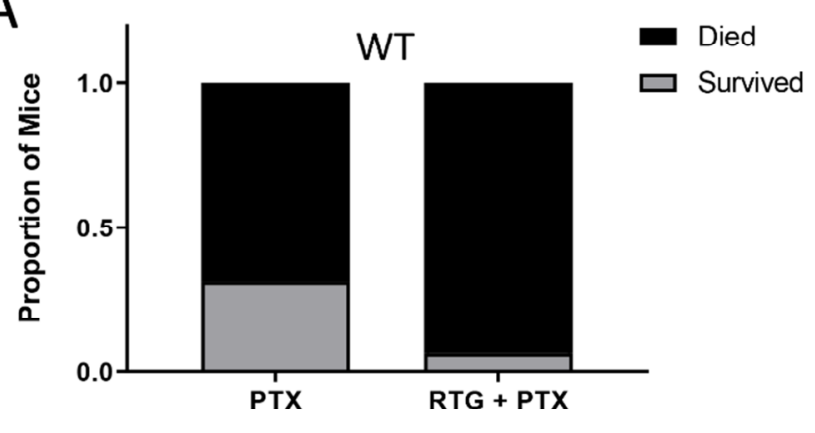

C

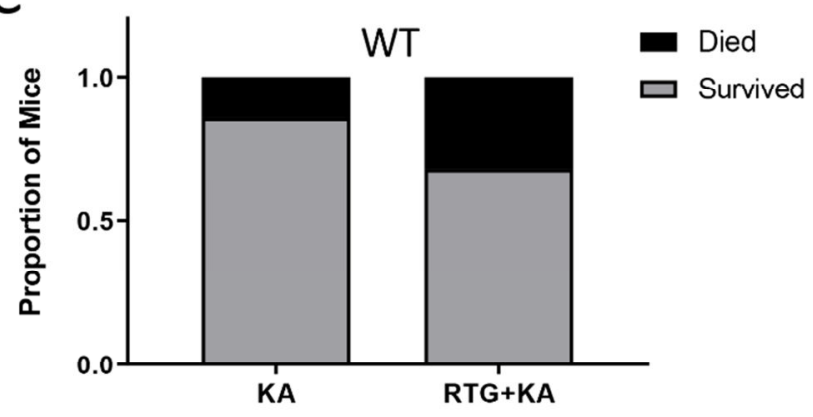

B

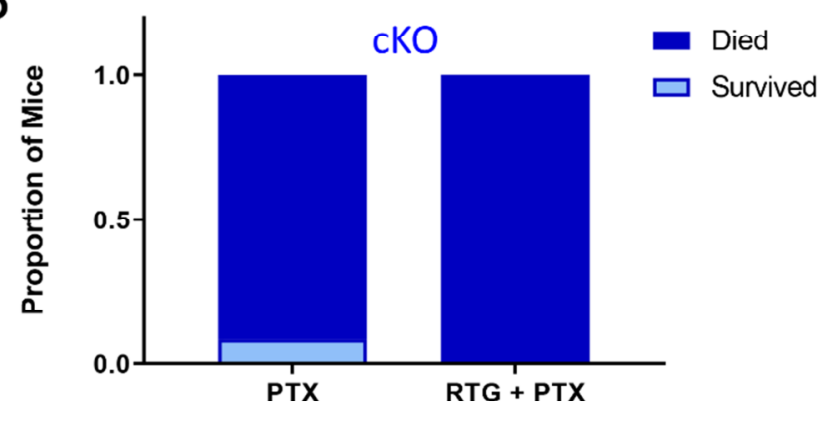

D

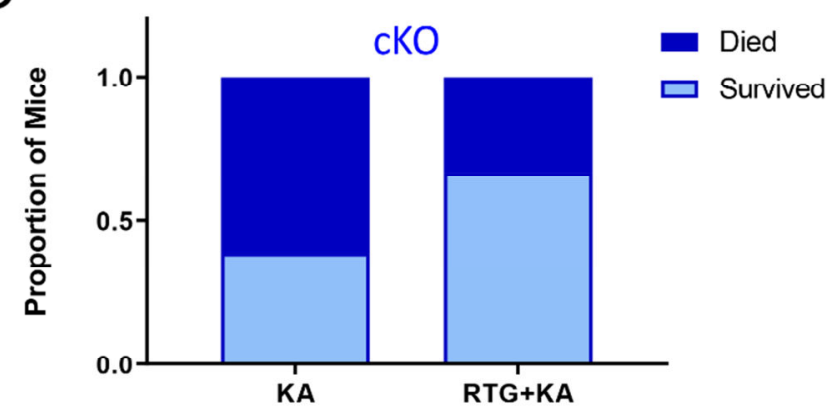

Figure S1. No change in seizure-induced mortality with RTG for cKO mice. Mortality following PTX-induced seizures was not significantly altered with RTG treatment in either (A) WT $(n=16,16)$ or (B) $c K O(n=12,14)$ mice. Mortality following KA-induced seizures was not significantly altered with RTG treatment in either (C) WT $(n=21,22)$ or $(D) c K O(n=18,18)$ mice. 
bioRxiv preprint doi: https://doi.org/10.1101/2020.12.09.417295; this version posted December 9, 2020. The copyright holder for this preprint (which was not certified by peer review) is the author/funder, who has granted bioRxiv a license to display the preprint in perpetuity. It is made available under aCC-BY-NC-ND 4.0 International license.

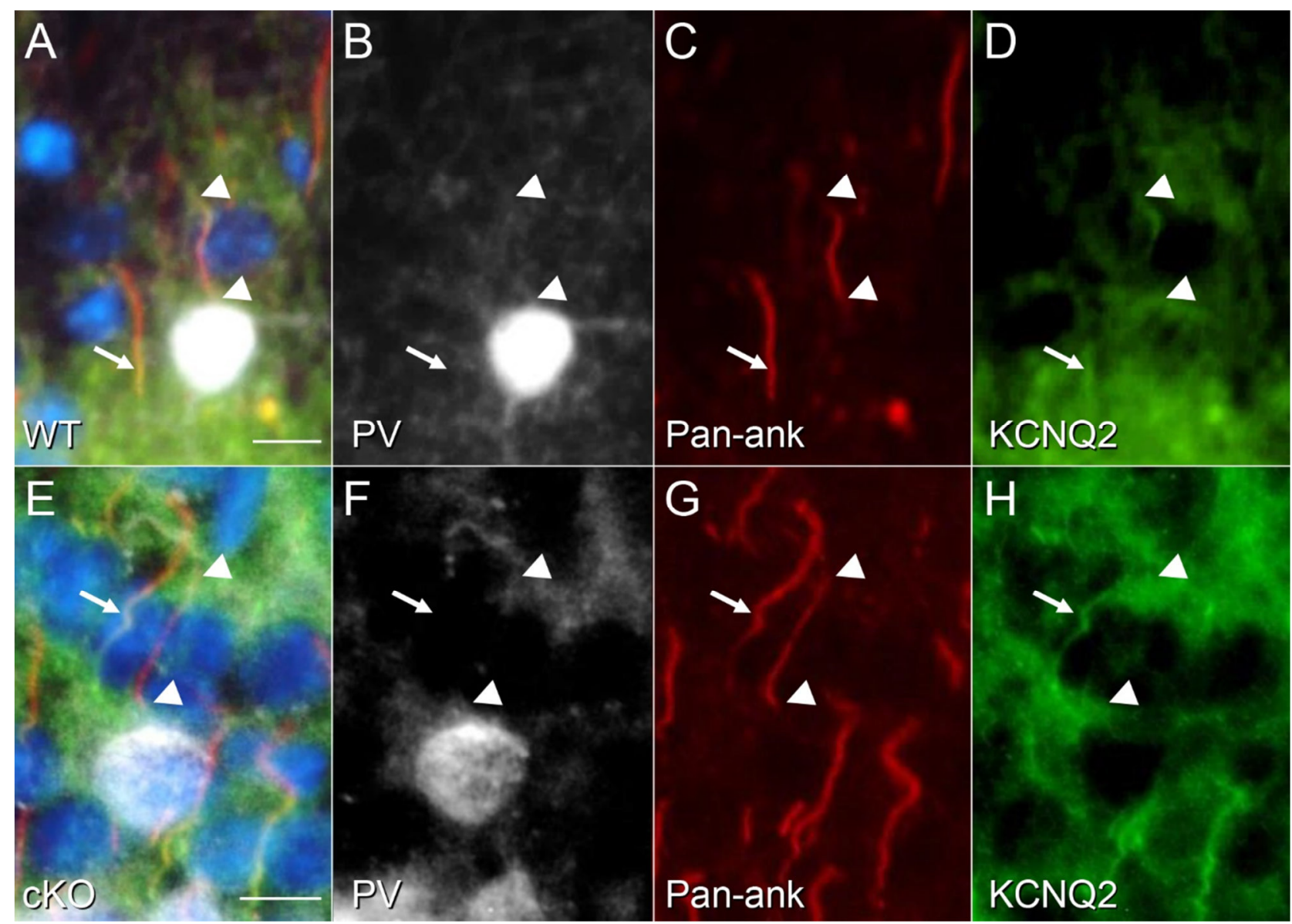

Figure S2. Selective deletion of KCNQ2 from cortical PV-IN in cKO mice. (A-D) In WT mice, KCNQ2 (green) was co-expressed with pan-ankyrin (red) at the distal axon initial segment (AIS) of PV-IN (TdTomato - pseudocolored in white), seen here in Layer 2 of the neocortex (arrowheads) as well as non-PV-IN (arrow). (E-H) In cKO mice, KCNQ2 was no longer co-expressed with pan-ankyrin in PVINs (arrowheads) but remained evident in the AIS of non-PV-INs (arrow); bar $=10 \mu \mathrm{m}$. 
bioRxiv preprint doi: https://doi.org/10.1101/2020.12.09.417295; this version posted December 9, 2020. The copyright holder for this preprint (which was not certified by peer review) is the author/funder, who has granted bioRxiv a license to display the preprint in perpetuity. It is made available under aCC-BY-NC-ND 4.0 International license.

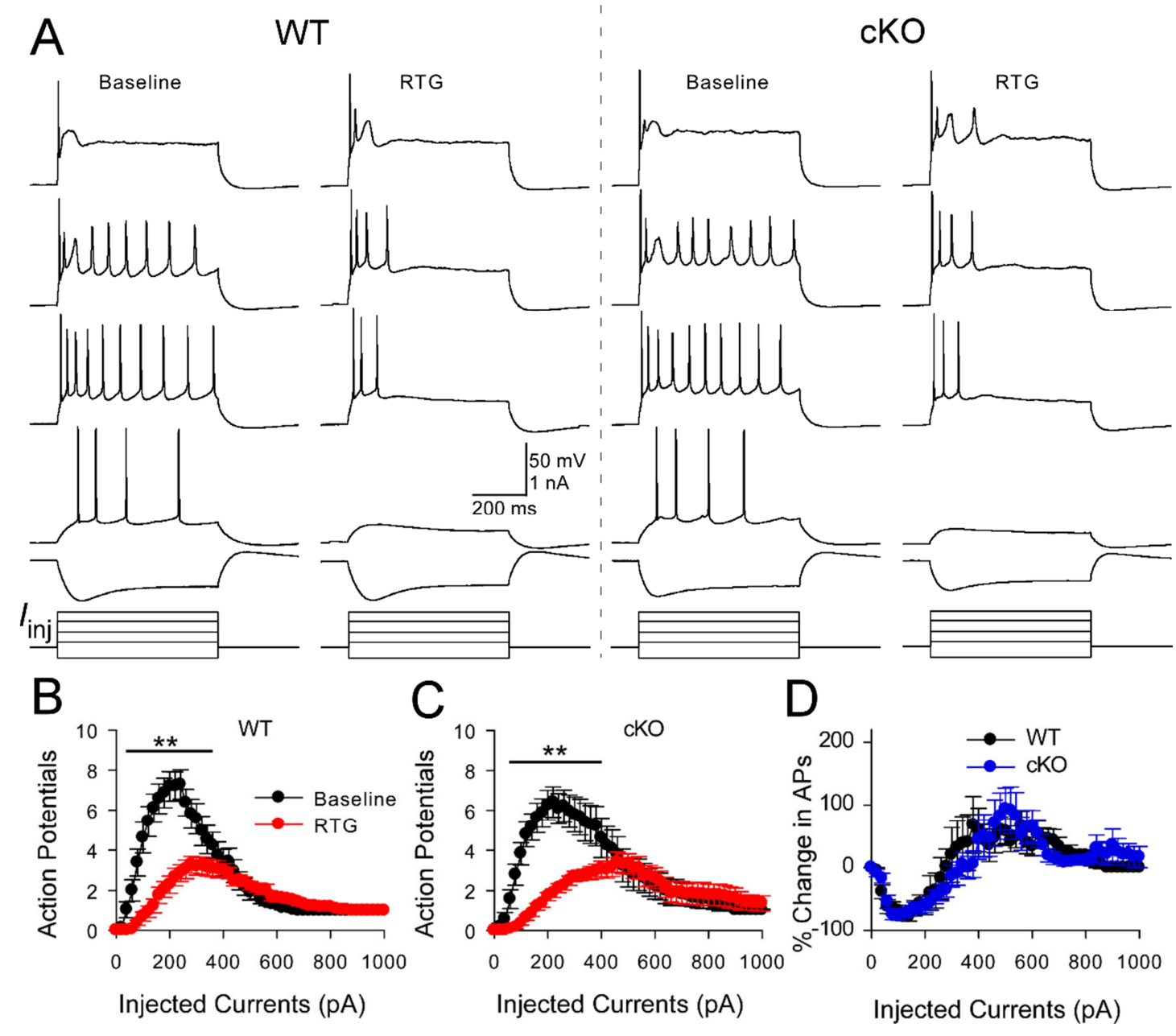

Figure S3. Effects of RTG on the neuronal excitability of hippocampal CA1-PCs in vitro. (A) Representative membrane voltage responses to different current step injections in CA1-PCs from WT (left) and cKO (right) mice before and after $10 \mu \mathrm{M}$ RTG treatment. RTG was effective in suppressing APs in WT PCs $\left(B, n=21,{ }^{* *} p<0.01\right.$ with repeated measures 2 -way ANOVA) and in cKO PCs $(C$, $n=24$, ${ }^{* *} p<0.01$ with repeated measures 2-way ANOVA). (D) The RTG-induced percentage change of AP number induced by different current injections did not show significant differences between the two genotypes ( $n=21$ in WT and n=24 in cKO mice). 
A
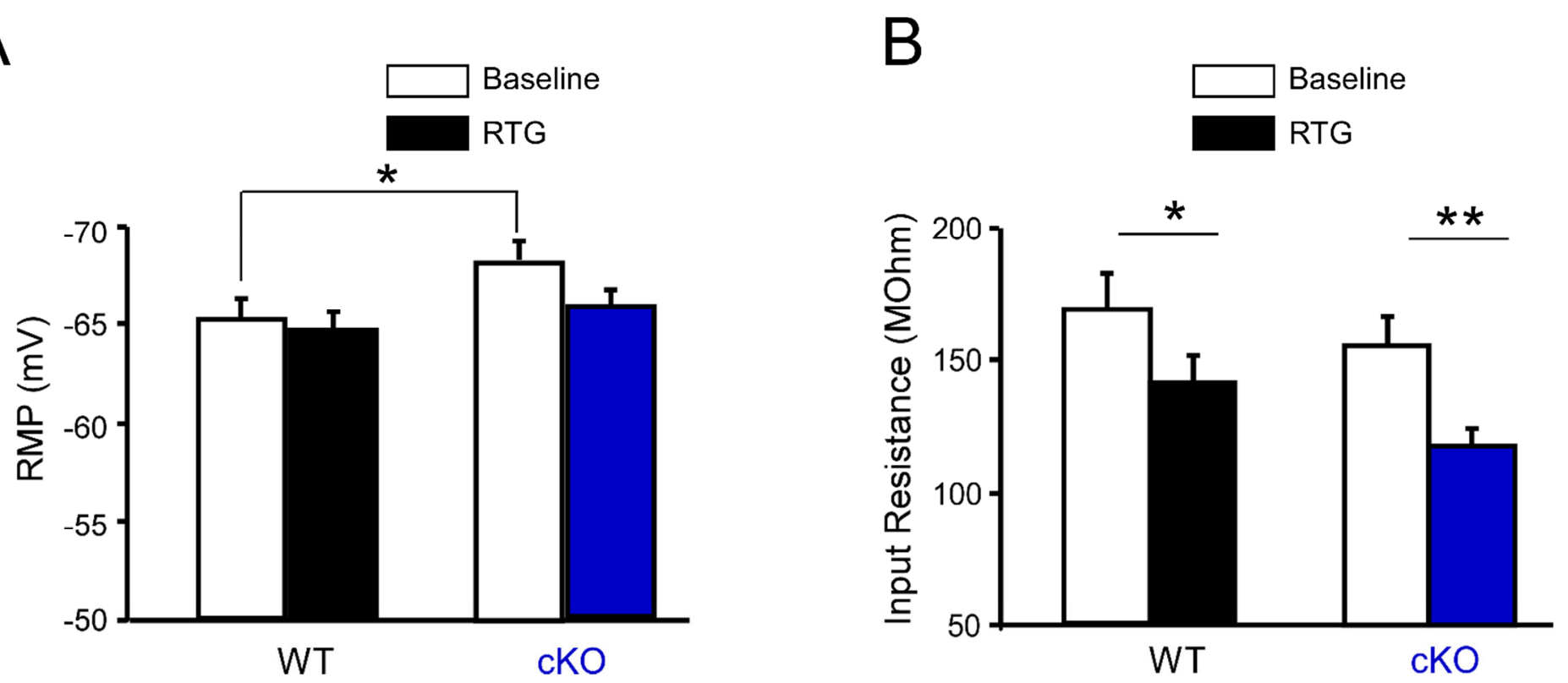

Figure S4. Effects of retigabine (RTG) on the passive membrane properties of hippocampal CA1-PCs in vitro. (A) Genotype had a significant effect on baseline RMP of CA1-PCs ( $\mathrm{n}=19$ for WT, $\left.\mathrm{n}=24 \mathrm{cKO},{ }^{*} p<0.05\right)$. Bath application of RTG in hippocampal slices did not significantly change RMP of CA1-PCs from either WT or CKO mice. (B) Bath application of RTG induced a significant reduction in input resistance of CA1-PCs from both $\mathrm{WT}$ and cKO mice ( $\mathrm{n}=19$ for $\left.\mathrm{WT}, \mathrm{n}=24 \mathrm{cKO},{ }^{* *} p<0.01,{ }^{*} p<0.05\right)$. 